\title{
Community Based Survey on Psychiatric Morbidity in Eastern Nepal
}

\author{
Pramod Mohan Shyangwa, ${ }^{1}$ Dhana Ratna Shakya, ${ }^{1}$ Baikuntha Raj Adhikari, ${ }^{1}$ Arun Kumar Pandey, ${ }^{1}$ Nidesh \\ Sapkota, 'Binod Kumar Deo, 'Surya Raj Niraula² \\ 'Department of Psychiatry, BPKIHS, Dharan, ${ }^{2}$ Department of Community Medicine, BPKIHS, Dharan, Nepal
}

\section{ABSTRACT}

Background: Mental health problem is common and ubiquitous. Mental illness cuts across all sections of society, irrespective of socio-economic status. Recent international survey showed a varying prevalence rates ranged (4.7\%-12.0\%). The Community study in Nepal yielded prevalence rate of mental illness at $14.0 \%$.

Methods: descriptive, epidemiologic study with systematic randomization sampling.

Results: Of 911 respondents majority was married (76.1\%), of age group 20-59 yrs. Overall, 113 $(12.4 \%)$ respondents had at least one psychiatric disorder and the commonest were: Depression, Anxiety disorders, Alcohol use disorders with 1.9\% had seizure/epilepsy.

Conclusions: Community prevalence rate of some common psychiatric disorders is high which calls for special attention to address depressive and alcohol related disorder from all quarters of society particularly from government.

Keywords: community survey; mental illness; psychiatric morbidity.

\section{INTRODUCTION}

Mental health problem is common and ubiquitous. Mental illness cuts across all sections of society throughout the globe, irrespectiveof its socio-economic status: rich or poor; educated or illiterate and gender status. However, some conditions are more prevalent in one geo-demographic population than others. For example, depressive disorder is more common in elderly and females. The World Health Organization (WHO) update in 2001 states that about 450 million people worldwide, meaning about one-fourth persons then, were sufferedfrom mental illness. ${ }^{1}$ Thesurvey analysis done by WHO showed that neuropsychiatric conditions (major mental illnesses and dementias) had an aggregate point prevalence of about $10 \%$ for adults. ${ }^{2}$ Recent robust international survey showed a varying, but high life-time prevalence of mental disorders that ranged from $47 \%$ in the US and $12.0 \%$ in Nigeria.
Projected lifetime risk of any disorder as of age 75 is between $17 \%$ in the US and $69 \%$ in Israel. ${ }^{3}$ India, the closest southern neighbor, which shares many sociocultural milieu with Nepal also has reported wide-ranged prevalence rates, between $9.5^{4}$ and $102^{5}$ per 1000 population.In Nepal, large-scale systematic communitybased psychiatric morbidity surveys are conspicuously scarce. Most of the studies are conducted in clinical, or specified settings e.g. old-age home, making it difficult to extrapolate prevalence estimatefor general population.A survey conducted in Kathmandu valley (capital city) in 1983 yielded prevalence rate of mental illness at 14.0\%. ${ }^{6}$ Another survey carried out using 'DSM-III-R criteria checklist', but limiting in only six disorders, on a small ethnic group (total 4200 individuals) of 'Jirel'

Correspondence: Prof. Pramod M. Shyangwa, I.O.M. $18 \mathrm{FI}$ Rajanakarn Bld. 183 South Sathorn, Bangkok-10120, Thailand. Email: shyangwap@yahoo.com, Phone: +66-845550337. 
community, revealed overall, $20.6 \%$ prevalence rate; and 'somatization disorder' being the highest $(11.8 \%) .^{7}$ The prevalence rate of 'conspicuous psychiatric morbidity' (CPM) was found to be $35.4 \%$ in two urban populations in western Nepal. ${ }^{8}$ Substance use/abuse, which intricately relates with mental health issues, is another emerging public health concern for Nepalese society. A community survey conducted using CAGE questionnaire in the town of Dharan, Nepal, found a high alcohol dependence rate-25.8\%.9 Yet another survey done in the same municipality found that about $17.0 \%$ females consumed alcohol. ${ }^{10}$ Beyond numbers; owing to disabling nature of many psychiatric illnesses, its impact on family accrues considerable burden to family and society at large. Globally the psychiatric morbidity together with neurological conditions account for $12.3 \%$ of global burden of disease as measured by DALY. ${ }^{1}$ Neuro-psychiatric disorders are estimated to contribute $11.0 \%$ of the global burden of disease in Nepal as per WHO. ${ }^{11}$ Although Nepal has made a remarkable progress towards achieving Millennium Development Goal (MDG) in health sector ${ }^{12}$ by improving maternal health and reducing child mortality rate, still much more needs to be done in mental health front. Government and public alike accord low priority for mental health issues as reflected on health budget that only $0.7 \%$ health budget is allocated for mental health sector ${ }^{11}$ and their slacked attitude towards mental health services in the country. In fact, investing in mental health will have rewarding dividend for individual, community and country at large. Among many, one of the key reasons for such state of lackluster is related to credible and comprehensive data on mental health. Understandably, systematic quality data at least, on some important mental disorders are needed to pave way for deserving allocation of resources.

Keeping above points in view, this community-based psychiatric morbidity survey was embarked on covering three topographically and socially different districts of eastern Nepal. This study is hoped to be a small, but firm step towards producing credible prevalence data on mental health.

\section{METHODS}

This study surveyed on adult individuals aged $18 \mathrm{yr}$ and above residing in three topographically and socioculturally distinct districts of eastern Nepal. Nepal is tremendously diverse in geographic and socio-cultural terms. It elevates from lowest land of less than 100 meter in Terai in the south towards high mountains in the north including world's highest peak-8848 meter above the sea level. There are 125 castes/ethnic groups who speak 123 languages. ${ }^{13}$ The socio-economic and cultural differences among them ranges from subtle to striking ones, which may have some influence on mental health conditions. Hence, three topological belts, namely Terai, Hill and mountain districts were selected.

\section{Sample size: 911}

Mountain (Sankhuwasabha)-300

Hill (Dhankutta)-302

Terai (Sunsari)-309

\section{Sampling procedure}

Probability sampling involving cluster and systematic randomization strategy has been adopted in this study. Three representative districts, one each from Mountainous, Hilly and Terai belt of eastern Nepal; Sangkhuwasabha (bordering to Tibet, China), Dhankutta and Sunsari (Bordering with state of Bihar, India) respectively were selected to make data more generalizable for at least, eastern Nepal. Before embarking on study, on site feasibility study was done and meetings were held with local authority and other potential stakeholders/ agencies. From each district, one village development committee (VDC) was selected, based on logistic feasibility and transport accessibility as some places (VDCs) in mountain and hilly district are not easily accessible. Two to three (depending on population size) wards (cluster) from each VDC were randomly selected. The official household lists were collected from local administrative authority. Households were determined applying systematic random sampling method. Primarily community resting places (raised platform) locally known as 'Chautara' was chosen as a 'start point', however, other landmarks like intersections, community temples or shrines were also used depending on feasibility. From start point, every third household was included for the study. All adult family members were included in the interview; except few cases, where all the members belonged to the same sex- this is to make study gender balanced. If three attempts to make contact with designated household residents were failed, the immediate next household was included for the study. The appropriate time of the day was chosen for interview as many residents were farmers and they spent most of their time the farms.

\section{Assessment}

The data was collected administering pretested questionnaire M.I.N.I. (Mini-International Neuropsychiatric Interview) by female enumerators.

M.I.N.I. is a short structured diagnostic interview schedule, developed jointly by psychiatrists and clinicians in the US and Europe for DSM-IV and ICD10 psychiatric disorders. The time duration criteria for qualifying a disorder is as outlines in DSM-IV. With an 
administration time of approximately 15 minutes, it is designed to meet the need for a short but accurate structured psychiatric interview for epidemiological studies and also is being used as a first step in outcome tracking in non-research clinical settings. It is widely used in clinical settings and epidemiological studies. ${ }^{14}$

The Nepalese-version of pre-tested MINI was used in this study. The Nepalese-version was developed following standard translation procedure: forwardbackwards translation, independently carried out by two native-speakers of Nepali language. Discrepancies and incongruences were resolved by third consultant by using consensus process. A short questionnaire tapping epilepsy/seizure was also added to MINI after reaching a consensus among investigators. Epilepsy/ seizure poses high morbidity (sometimes mortality) and family burden due to magico-religious explanation of disease and stigma surrounded to it leading to poor help-seeking behavior and devoid of modern treatment.

\section{Enumerators:}

Three female enumerators (lay trained) were selected from respective localities (district), who were well familiar with local culture and social milieu. They all had health background as their professional education with CMA (Certificate Medical Assistance) and ANM (Axillary Nurse Midwife) certification. They had also involved in similar work (health survey)previous. They were trained for one week by investigators for this work. Some clinical cases were also discussed during training for practical experience and better understanding.

\section{Supervision and monitoring:}

In order for quality study regular supervision and monitoring is essential. At site, random observation of data collection process was done by the one of the investigators now and then. Difficulties and challenges were sorted out and flaws were rectified then and there. If necessary feedbacks and opinions were taken from enrolled and interviewed subjects.

\section{Data Management \& Analysis:}

The collected data were fed and managed in Excel. Crosscheck was done for missing or wrong entries and flaws were corrected accordingly with the assistance of statistician. The data were analyzed applying parametric techniques. Means, percentage, proportions were calculated.

\section{Ethical consideration:}

The study was carried out after the approval of the local 'Institute ethical review board' of BP Koirala institute of health sciences, Nepal. The informed consent was obtained from the respondents, but if respondent was not in the position to provide it due to severe mental illness, absence of insight, lack of judgement or not in capacity to give informed consent, the consent was obtained from immediate caregiver or guardian. The confidentiality was maintained. The information collected was used for research or individual case management purpose only.

\section{RESULTS}

A total of 911 respondents were enrolled from 26 villages (Tol) of 16 wards from three VDC ( Village Development Committee) of three districts, one each from Mountain (Sankhuwasabha-300), Hill ( Dhankutta-302) and Terai (Sunsari-309) geographical belt of Nepal. Gender wise, females constituted 461 $(50.6 \%)$, with M:F ratio of $0.97: 1$

Majority was married 694 (76.1\%), followed by single $159(17.4 \%)$, widow 31 (3.4\%), divorced $4(0.4 \%)$, separated $3(0.3 \%)$ and $20(2.2 \%)$ - did not respond.

Majority of the subjects $(82.0 \%)$ were in the age group of 20-59 years. Average age of respondents: 35.1 Yr. (Min.14 -Max. 79 yr.). Average age of the household head was $45.6 \mathrm{yr}$ with min. 18 and maximum 79yr. There is no clear majority of any caste indicating a homogeneous society in terms of caste\#( \# Still some remnant of caste system is existent in Nepal). Followers of Hinduism predominated 731 (80.2\%) among the respondents. Buddhist were $73(8.0 \%)$; Kirat 72 (7.9\%); Muslims 20 (20.1\%) and Christians 15 (1.7\%)

According to education level: $28.0 \%$ were illiterate and $26.0 \%$ were 'just literate'.Most common occupations were; farming $(61.0 \%)$, business $(8.0 \%)$ and service $(6.0 \%)$. Around $30.0 \%$ of Nepalese from eastern Nepal have nuclear family however, majority lived in joint/ nuclear family 620 (68.0\%). Twenty-four (2.7\%) did not answer. The average household size in Nepal is 4.88 (Census, 2011). Out of 911 respondents, 281 had varying family size(average: 1.59 with range $1-7$ ) working away from home; either within the country or abroad. Twenty-one $(2.3 \%)$ respondents revealed suicidality with mild in $16(1.8 \%)$, moderate in $3(0.3 \%)$ and severe in $2(0.2 \%)$.

Overall, $113(12.4 \%)$ respondents had at least one psychiatric disorder as per M.I.N.I. schedule at the time of assessment. The commonest were being Depression, Anxiety disorders, Alcohol use disorders. Eighteen $(1.9 \%)$ subjects reported to have seizure/epilepsy during interview.

Combining seizure/epilepsy, overall, prevalence for 
Shyangwa et al. Community Based Survey on Psychiatric Morbidity in Eastern Nepal

neuropsychiatric disorders stands at $14.4 \%$.

\begin{tabular}{|c|c|c|}
\hline Age ( in Years) & Frequency (no.) & Percentage (\%) \\
\hline$<20$ & 108 & 11.8 \\
\hline $20-29$ & 289 & 31.7 \\
\hline $30-39$ & 182 & 19.9 \\
\hline $40-49$ & 153 & 16.7 \\
\hline $50-59$ & 125 & 13.7 \\
\hline $60-69$ & 45 & 4.9 \\
\hline$>70$ & 9 & 0.9 \\
\hline \multicolumn{3}{|l|}{ Caste: } \\
\hline Brahmin & 142 & 15.9 \\
\hline Chhetri & 69 & 7.5 \\
\hline Rai & 44 & 4.8 \\
\hline Limbu & 87 & 9.5 \\
\hline Tamang & 22 & 2.4 \\
\hline Newar & 13 & 1.4 \\
\hline Dalit/Advantaged & 230 & 25.2 \\
\hline Others & 304 & 33.3 \\
\hline \multicolumn{3}{|l|}{ Gender: } \\
\hline Male & 450 & 49.3 \\
\hline Female & 461 & 50.6 \\
\hline \multicolumn{3}{|l|}{ Religion } \\
\hline Hindu & 731 & 80.0 \\
\hline Buddhist & 73 & 8.0 \\
\hline Kirat & 72 & 7.9 \\
\hline Muslim & 20 & 2.1 \\
\hline Christian & 15 & 1.6 \\
\hline \multicolumn{3}{|l|}{ Marital Status } \\
\hline Married & 694 & 76.1 \\
\hline Single & 159 & 17.4 \\
\hline widow & 31 & 3.4 \\
\hline Divorced & 4 & 0.4 \\
\hline Separated & 3 & 0.3 \\
\hline No response & 20 & 2.2 \\
\hline \multicolumn{3}{|l|}{ Family Structure } \\
\hline Joint Family & 620 & 68.0 \\
\hline Nuclear & 267 & 29.3 \\
\hline No response & 24 & 2.6 \\
\hline Education Status & Frequency (no.) & Percentage (\%) \\
\hline Illiterate & 257 & 28.2 \\
\hline Literate & 238 & 26.1 \\
\hline $\begin{array}{l}\text { Primary ( up to } 5 \\
\text { grade) }\end{array}$ & 136 & 14.9 \\
\hline $\begin{array}{l}\text { Secondary } \quad(6-10 \\
\text { grade) }\end{array}$ & 161 & 17.6 \\
\hline
\end{tabular}

\begin{tabular}{|lll|}
$\begin{array}{l}\text { Higher secondary } \\
\text { (+2) }\end{array}$ & 84 & 9.2 \\
Graduate & 17 & 1.8 \\
$\begin{array}{l}\text { Post Graduate } \\
\text { above }\end{array}$ & 4 & 0.4 \\
No response & 14 & 1.5 \\
Occupation & & \\
unemployed & 23 & 2.5 \\
Service & 53 & 5.8 \\
Skilled worker & 17 & 1.8 \\
Student & 32 & 3.5 \\
Home maker & 103 & 11.3 \\
Farming & 552 & 60.5 \\
Professional & 17 & 1.8 \\
Business & 71 & 7.7 \\
Unskilled/labor & 21 & 2.3 \\
Not responded & 22 & 2.4 \\
\hline
\end{tabular}

\begin{tabular}{|lll|}
\hline Table 2. Psychiatric Diagnosis. & & \\
\hline Overall, psychiatric prevalence & 113 & 12.4 \\
Clinical Depression & 53 & 5.8 \\
Mania/Hypomania & 3 & 0.3 \\
Psychosis ( Non-affective) & 3 & 0.3 \\
Panic disorder with agoraphobia & 5 & 0.5 \\
Panic disorder without agoraphobia & 30 & 3.2 \\
Agoraphobia & 2 & 0.2 \\
Social phobia & 2 & 0.2 \\
OCD & 7 & 0.7 \\
PTSD & 12 & 1.3 \\
GAD & 6 & 0.6 \\
Alcohol use dis. ( Dependence & 37 & 4.1 \\
+ Abuse) & & \\
Other Substance Use Disorder & 4 & 0.4 \\
Multiple Reponses\# & & $17.6 \#$ \\
Neurological condition & & \\
Epilepsy/Seizure & 18 & 1.9 \\
Total Neuro-psychiatric disorder & 131 & 14.3 \\
Suicidality* & 21 & $2.3 \%$ \\
\hline
\end{tabular}

*Note: Mild-1.8\%; Moderate-0.3\%; Severe-0.2\%

\section{DISCUSSION}

This is a community based epidemiological study, conducted on adult population in three geo-socioculturally diverse locales of eastern region of Nepal with an aim to establish psychiatric morbidity pattern including seizure/epilepsy and substance use/abuse. About twelve and a half adult population was found to have psychiatric disorder with major depression 
being the commonest $(5.8 \%)$ followed by alcohol dependence/abuse and panic disorder. Although psychiatric morbidity is more or less uniformly distributes worldwide, there are some variation in prevalence concerningliving situations, circumstances and risk population. Combined with seizure/epilepsy and general psychiatric prevalence, neuropsychiatric prevalence rate stands at $16.5 \%$. Although MINI, does not contain Seizure/Epilepsy as a category, because of clinical and public health importance a pre-set 'Seizure/ epilepsy' questionnaire was administered. If 'suicidality' ('suicidal thought' is not a disorder per se) also consider one of the morbidities as it is included in MINI, the overall psychiatric prevalence ratewould rise to make almost seventeen percent.

Of late, a growing number of researches are being carried out in Nepal in mental health field. Majority of them are hospital, ${ }^{15}$ special clinic $^{16}$ institute ${ }^{17}$ institution (oldage home $)^{18}$ based profiles andpsychiatric co-morbidity studies, which point towards considerable morbidity (burden) and disability. However, by the virtue of study design and limitations, the findings from such studies cannot be readily generalized to general population. Nonetheless, they can substantially contribute to triangulation for estimation of overall magnitude of problem when combined with epidemiologic studies. One community based preliminary survey was done in 1983 in Kathmandu valley that revealed a prevalence rate in the tune of $14 \%$. The prevalence rate in our study is quite similar to the above finding. ${ }^{6}$ other studies carried out in Jirel ethnic group and in small townships in western Nepal showed rate $20.4 \%$ and $35.5 \%$ respectively. ${ }^{7,8}$ These prevalence rate variation can be due to methodological differences. When compared to well conducted multisite international study, this study findings are more closer to psychiatric morbidity prevalence of Asian countries, like Japan-8.8\%, China (Beijing)-9.1\% than western countries-the USA posted $26.4 \% .{ }^{3}$ A recent systematic reviews done in India on 'the epidemiology of psychiatric disorders' screened out scientifically rigorous surveys only, concluded that the prevalence rate is ranged between $9.5^{4}$ and $102^{5}$ per 1000 population i.e. $0.9-10.2 \%$. Now psychiatric epidemiological data are more realistic than two-three decades ago thanks to improvement in measurement tools, descriptive issues (caseness, criteria) being resolved and more analytical questions are being addressed. $^{3}$

The diagnoses breakdown of our study revealed preponderance of depressive disorder (5\%), anxiety disorders $(4.1 \%)$, alcohol dependence $(4.1 \%)$ and substance use disorder which is consistent with the landmark prevalence study 'epidemiologic catchment area study'. ${ }^{19}$ The greater risk of depression among women is well established worldwide. Several hypotheses are postulated including psychosocial stressor, help-seeking behavior, and hormonalupheaval among many. Though 'suicidality' was not probed in detail, the possibility of depressive or other major illness are highly likely as depression and suicidal thoughts is closely associated. Anxiety disorders are reported to be one of the commonest psychiatry disorders in the community. ${ }^{20}$ Compared with the US data, where 12-month prevalence of anxiety disorders was $17.7 \%$, our rate is quite low. Overall, Generalized Anxiety Disorders (GAD) are the commonest among anxiety disorders, but in the index panic disorder, 'panic disorder without agoraphobia' were the commonest one and we have no explanation why is so. In a community survey in Jiri, depression and anxiety disorders were reported to be slightly lesser than the current study but they found lifetime somatization disorder as the commonest with the rate of $11.8 \% .{ }^{7}$ As for alcohol dependence/ abuse, our finding is almost similar to ECA study; however, it is much lesser than findings found in Dharantown..$^{9,10}$ Considering tolerant, or even encouraging sociocultural and religious milieu, the current finding was well expected. Suicide phenomena are usually difficult to detect, hence under reported, though this is one of the major concerns for psychiatric emergency in clinical setting and society alike. Some places of the eastern part of Nepal is known for higher prevalence of suicide. ${ }^{20}$ Though we lack a comprehensive community study for suicide, this finding to some extent compliments the suicide rate reported in a village of Lalitpur. ${ }^{22}$ Around $2 \%$ seizure/epilepsy rate was found in this study, which is slightly lower than a cumulative incidence of $3.1 \%$ reported in Minnesota US. ${ }^{23}$ A community survey conducted in Morang, proximate to current study showed a prevalence of epilepsy of 7.5 per 1000 with male-6.8 and female-7.9/1000 population ${ }^{24}$ that too is lower than current finding. Other psychiatric categories like mania, psychosis, obsessive-compulsive disorders were less common in this study, well within the expectation.

In the wake of decade-long political conflict, ${ }^{25}$ ongoing internal migration, circumstances forcing for foreign job and consequent social disintegration along with frequent natural disasters ${ }^{26}$ the rate of mental health problem is anticipated to be higher; however, we lack (pre-event) baseline data to compare with and furthermore, these factors were not analyzed (included) in the study. This survey endeavored to generate psychiatric morbidity in general adult population in eastern part of Nepal adopting standard study design and questionnaire with an expectation to fill up, to small extent, the existing gap in psychiatric epidemiology. Despite limitations;owing to methodological strength (randomization), comprehensiveness in information 
gatheringby trained interviewersmakesfindings reliable and can be viewed as a trustworthy preliminary -community based psychiatric prevalence study. We used 'Mini International Neuropsychiatric Interview (MINI)' for the diagnosis of common mental disorders ( depression, mania/hypomania, psychosis, organic psychiatric disorder, GAD, panic disorder with and without agoraphobia, agoraphobia, social phobia, OCD, PTSD, alcohol and other substance abuse/dependence). Some disorders originally included in the MINI are considered not significant for our context e.g. eating disorders, therefore they were excluded. Many others, probably common to our context e.g. dissociative, somatoform, adjustment, childhood disorders including mental retardation were not included in this survey since they were not included in the MINI. Hence, the overall prevalence rate is likely to be higher than what this study had generated. Another limitation of this study is the use of unvalidated MINI; understandably, the validating process itself is highly costly and time consuming. However, attempts were made to make it more reliable (valid) in local context by seeking expert opinions and reaching to consensual agreement on any disputed issues along with pre-testing.

In the future, large-scale, population based studies, using internationally accepted and locally validated comprehensive tool like, SCID-I, CIDI needs to be
considered.Beyond estimation of disorder prevalence, analytical studies to address such practical questions like burden of disease, risk factors, help-seeking behaviors, treatment coverage needs to be studied to estimate treatment gap and devise better response to mental health problem. Similarly, epidemiological surveys on substance use/abuse, children's and elderly people's mental health conditions are essential for obtaining a comprehensive picture of mental health situation in the country.

\section{CONCLUSIONS}

This study has generated prevalence rate of some common psychiatric disorders along with seizure/ epilepsy among representative adult population of eastern Nepal. The data highlights theextensiveness of depression and alcohol abuse/dependence in the society, thereby calling for concrete strategy and plan/policy to tackle these problems as a priority. The government has to stride for capacity building and upscale the program to address other mental health problems as well. This study hopes to be a small step forward in the mental health filed to open up bigger horizon.

\section{ACKNOWLEDGEMENTS}

This study was supported by Govt. of India, IAA, based in B.P. Koirala Institute of Health Sciences, Dharan, Nepal

\section{REFERENCES}

1. World Health Organization Bulletin. Mental Health: New understanding, new hopes, 2001. WHO, Jeneva.

2. Colin D. Mathers, Claudia Stein, Doris Ma Fat, ChalapatiRao, et al. Gobal Burden of Disease 2000: Version 2, Methods and Results, In: WHO Bulletin (2001)

3. Kessler RC,Angermeyer M, James C, Anthony et al. World Psychiatry 2007; 6: 168-176

4. Surya NC, Mental morbidity in Pondichery, Transaction-4, Banglore: All India Institute of Mental Health, 1964

5. Nandi DN, Ajmany S, Ganguly H, Banarjee G et al. Psychiatric disorders in a rural community in West Bengal: An epidemiological study. Indian J Psychiatry 1975; 17:87-99

6. Shrestha DM. A survey of Kathmandu Valley. Cited in: Wright C (1988) community mental health service in Nepalearly experiences (Proceedings of the workshop on National Mental Health Planning) Kathmandu, Dec 30, 1987-Jan 1, 1988

7. TausingM, Subedi S, Subedi J, Ross J et al. Contribution to Nepalese Studies, The Jirel Issue (January, 2000), 105-115.

8. Upadhyaya KD and Pol K. A mental health prevalence survey in two developing towns of western region. J. Nepal Med Assoc., 2003; 42: 328-330
9. Jhingan HP, Shyangwa PM, Sharma A, Prasad KMR et.al. Prevalence of alcohol dependence by the CAGE questionnaire. Addiction 2003: 98: 339-343

10. Niraula SR, Shyangwa PM, Jha N, Paudel RK, Pokharel PK. Alcohol Use among women in a town of eastern Nepal. JNMA 2004; 43, 244-249

11. World Health Organization.Nepal: Mental Health Atlas 2011-Department of Mental Health and Substance Abuse 2011. WHO, Geneva

12. UN (United Nations) in Nepal: News Insight, Vol. 50, Feb-Mar, 2013. [internet] [Accessed at 16:05 on 5/9/13]

13. Nepal Census, Central Bureau of Statistics, Govt. of Nepal 2011. Kathmandu, Nepal

14. Sheehan DV, Lecrubier $\mathrm{Y}$, Sheehan $\mathrm{KH}$, et al. "The Mini-International Neuropsychiatric Interview (M.I.N.I.): the development and validation of a structured diagnostic psychiatric interview for DSM-IV and ICD-10". J Clin Psychiatry 1998; 59 Suppl 20: 22-33

15. Shakya DR, Pandey AK, Shyangwa PM, et al. Psychiatric morbidity profile of referred psychiatry OPD patients in a general hospital. Indian Medical Journal2009; 103 (12):407-411 
16. Shakya DR, Maskey R, Sharma SK, Karki P. Psychiatric problem in Clinic-Diabetes mellitus patients. Fourth Diabetes India International Conference. April 15-17, 2011, New Delhi, India2011; ( Paper presented)

17. Shakya DR, Lama S, Karki P et al. Psychiatric disorders among adult 'people living with HIV/AIDS' attending a tertiary care hospital in the eastern Nepal, BPKIHS.Journal of Diabetelogy2012 (June); 2:4

18. Harish Chandra Ghimire, et al Are elderly living in old age home, less depressed than those of community? From a comparative study. Journal of Chitwan Medical College 2012;1 (2); 5-8

19. Rigier DA, Myers JK, Kramer M, Robins LN, Blazer DG, Hough RL, et al. The NIMH Epidemiologic Catchment Area Program: Historical context, major objectives, and population characteristics.Archieves of General Psychiatry; 1984;41, 943-941

20. Kessler RC, Chiu WT, Jin R, Ruscio AM, et al. The epidemiology of panic attacks, panic disorders, and agoraphobia in the National Comorbidity Survey replication. Archieves of General Psychiatry 2006;63: 415-424.
21. Shakya DR, Shyangwa PM, Shakya R. Psychiatric emergencies in a tertiary care hospital. Journal of Nepal Medical Association2008; 47 (169): 20-33.

22. Thapa B, Carlough MC. Suicide incident in Lalitpur district of central Nepal. Trop Doct. October 2000;30(4): 200-203.

23. Hauser WA, Annegers JF, Kurland LT. Incidence ofepilepsy and unprovoked seizures in Rochester, Minnesota: 1935-1984. Epilepsia1993; 34 (3): 453-468.

24. NepalMK,Sharma VDandShrestha PM. Epilepsy prevalence, a case study of Morang district. International Workshop on "Epilepsy" conducted jointly by EPICADE-epilepsy care developing countries and department of psychiatry, IOM. April 15, 1996, Kathmandu, Nepal, 17-23.

25. Shakya DR, Lamichhane N, Shyangwa PM, Shakya R. Psychiatry morbidity with armed conflict-related stressor. Health Rennaissance2011;9 (2):67-72.

26. Karn R, Jha N, Shakya DR et al. Effect of SaptaKoshi Flood on Mental Health among the victims in Sunsari, Nepal. (Unpublished Thesis of Master of Public Health (MPH), submitted to BPKIHS). 